\title{
Reuni e Expansão Universitária na UFMG de 2008 a 2012
}

\author{
Edileusa Esteves Lima' \\ Lucília Regina de Souza Machado' \\ 'Centro Universitário UNA, Belo Horizonte/MG - Brasil
}

RESUMO - Reuni e Expansão Universitária na UFMG de 2008 a 2012 . Este artigo tem como objetivo analisar em que nível de cumprimento as metas da UFMG apresentadas ao MEC, em 2008, para o Reuni, encontravam-se em 2012, assim como as mudanças que se produziram no contexto institucional como decorrência da expansão universitária induzida por esse Programa. Foram consultados documentos referentes ao Programa Reuni e analisados os dados institucionais divulgados pela UFMG em sua página na internet e em seu Relatório de Gestão 2011. Os resultados dessa pesquisa mostram que a UFMG cumpriu quase integralmente suas propostas de criação de novos cursos e expansão de vagas. Porém, intercorrências e agravamento de situações críticas surgiram e requerem atenção da gestão universitária.

Palavras-chave: Reuni. Expansão Universitária. Qualidade de Ensino.

ABSTRACT - Reuni and University Expansion in UFMG from 2008 to 2012. This article aims to analyse how well the goals of Universidade Federal de Minas Gerais (UFMG) presented to the Ministry of Education (MEC) in 2008 for the Program of Support to Restructuration and Expansion Plans (Reuni) were achieved in 2012, as well as the changes that occurred in the institutional context as a result of the university expansion induced by this program. Documents related to the REUNI program were examined and the institutional data published by UFMG in its website and in its Annual Report from 2011 were analysed. The results of this research show that UFMG fulfilled almost entirely its proposals for new programs and expansion of vacancies. However, unexpected events and worsening of critical situations have arisen and require attention of university management. Keywords: Reuni. University Expansion. Teaching Quality.

Educação \& Realidade, Porto Alegre, v. 41, n. 2, p. 383-406, abr./jun. 2016. 383 http://dx.doi.org/10.1590/2175-623654765 


\section{Introdução}

O Programa de Apoio a Planos de Reestruturação e Expansão das Universidades Federais Brasileiras (Reuni) foi apresentado às universidades federais em 2008 e conseguiu nesse mesmo ano a adesão das 59 universidades federais do país. A Universidade Federal de Minas Gerais (UFMG) apresentou seus compromissos, considerando o prazo de cinco anos para cumpri-los.

Como em 2012 o prazo acordado chegou ao fim, realizou-se uma pesquisa para verificar se as metas de criação de novos cursos e expansão de vagas assumidas pela UFMG foram realmente cumpridas e que resultados se produziram no contexto institucional que merecem atenção da gestão universitária.

A pesquisa retomou o Decreto n. 6.096, de 24 de abril de 2007 (Brasil, 2007a), da Presidência da República, que apresentou as metas do Programa Reuni, fez interlocução com autores que discutem a dialética entre qualidade da educação e expansão de vagas, recuperou a proposta da UFMG apresentada em 2008 e analisou dados sobre cumprimento de metas e questões decorrentes da expansão induzida. Constatou-se que a UFMG cumpriu quase integralmente o que ela propôs para a criação de novos cursos e expansão de vagas. Há, contudo, vulnerabilidades que comprometem seus feitos.

\section{O Programa Reuni}

O Reuni faz parte do Plano de Desenvolvimento da Educação (PDE) e foi instituído em 6 de abril de 2007 pelo Decreto Presidencial n. 6.096, sob o pressuposto do importante papel das universidades federais no desenvolvimento econômico e social do país. Sua principal finalidade é reduzir as desigualdades sociais com relação ao acesso e à permanência no ensino superior. Para tanto, conforme consta nesse Decreto (Brasil, 2007a), o Governo Federal cogitou alcançar, em cinco anos, a meta de $30 \%$ de jovens, entre 18 e 24 anos, matriculados no ensino superior. Em 2007, esse percentual se encontrava na casa dos $13,1 \%$, ou seja, 86,9\% dos brasileiros entre 18 e 24 anos não cursavam esse nível de ensino. O Reuni estabeleceu também a meta de elevar a taxa de conclusão média em cursos de graduação para $90 \%$ e a relação de um professor para dezoito alunos de graduação em cursos presenciais.

Ainda de acordo com o Decreto Presidencial n. 6.096, de 24 de abril de 2007 (Brasil, 2007a), foram traçados objetivos de ampliação do acesso à educação superior por meio de promoção do aumento das vagas em cursos de graduação, de oferta de cursos noturnos e de ocupação de vagas ociosas. Propôs o incentivo às inovações pedagógicas e o combate à evasão como estratégias de elevação das condições de permanência e sucesso dos alunos nesse nível de ensino. 
Pinto (2004), com base em dados do MEC/Inep, apresenta a evolução da matrícula na educação superior de graduação presencial, por categoria administrativa, no Brasil, de 1960 a 2002. Os dados oferecidos permitem apurar que, entre 1990 e 2002, houve um aumento de 125,95\% de estudantes no ensino superior no país. Isso ocorreu graças à elevação da escolarização da população, ao aumento de concluintes no ensino médio e às facilidades proporcionadas pelas políticas de flexibilização e regulamentação da educação superior, implementadas na década de 1990 pelo Governo Federal. No entanto, o percentual dos matriculados nas IES públicas ainda permaneceu bem inferior ao da rede privada, como se vê abaixo:

Gráfico 1 - Evolução da Matrícula na Educação Superior de Graduação por Dependência Administrativa (Brasil 1980-2011)

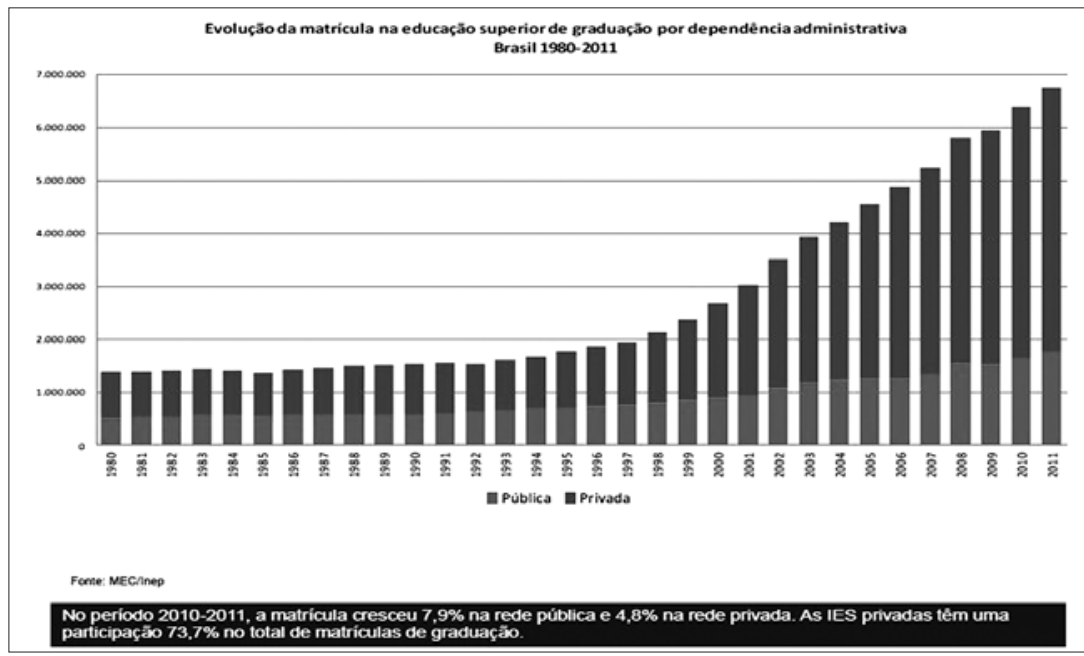

Fonte: Brasil. MEC. Inep (2011).

Até 2010, de acordo com o Censo da Educação Superior de 2011 (Brasil, 2012a), a matrícula na rede pública de educação superior tinha um crescimento inferior à da rede privada. Mas, de 2010 a 2011, ela experimentou um maior crescimento (7,9\%) nas instituições públicas, enquanto que nas instituições privadas o incremento ficou em 4,8\%. Esses dados já indicam uma avaliação positiva do cumprimento das metas do Reuni.

O Censo da Educação Superior de 2011 aponta ainda que a matrícula na rede federal cresceu $10 \%$ entre 2010 e 2011, elevando sua participação para mais de $58 \%$ das matrículas na rede pública, com um pouco mais de um milhão de alunos. Já o Censo da Educação Superior de 2013 (Brasil, 2014) constatou que, no período 2012-2013, a matrícula na rede federal cresceu 4,6\% e já tinha 58,9\% de participação na rede pública, superando a marca de 1,13 milhão de matrículas. O Censo da Educação 
Superior de 2013 informou também que o percentual de pessoas frequentando a educação superior em 2012 já representava quase 30\% da população brasileira na faixa etária de 18 a 24 anos, aproximando do cumprimento de uma das metas do Reuni que é a de atingir os $30 \%$.

Analisando o Censo da Educação Superior de 2013, verificou-se que, nos últimos 10 anos, a taxa média de crescimento anual de matrículas foi de 5,0\% na rede pública e $6,0 \%$ na rede privada. Em 2013, a rede privada teve uma participação superior a $80 \%$ no número de ingressos nos cursos de graduação. Ou seja, o crescimento das matrículas na rede pública ainda é significativo, mas voltou a ser superado pela rede privada.

Em relação à mobilidade estudantil, o Reuni a definiu como “[...] importante estratégia de construção de novos saberes, de vivência de outras culturas, de valorização e respeito ao diferente" (Brasil, 2007b, p. 5). Para tanto, tornou-se necessário investir em políticas de inclusão e de assistência estudantil, tendo em vista a democratização do acesso e permanência e a efetiva igualdade de oportunidades. Para 2011, se previu o investimento de R 395 milhões para as ações de assistência por meio do PNAES (Programa Nacional de Assistência Estudantil). A assistência estudantil, para o Reuni, “[...] está diretamente associada à inclusão, democratização do acesso e permanência de forma a promover a efetiva igualdade de oportunidades, compreendidas como partes integrantes de um projeto de nação" (Brasil, 2007b, p. 6).

Dos projetos apresentados pelas 59 IFES ao MEC, destaca-se a criação de cursos de graduação noturnos, com caráter de demanda social, direcionados a atrair alunos carentes. Esse novo perfil de estudante de IFES traz para essas instituições demandas diferenciadas que exigem adaptações diversas, principalmente, no que dizem respeito às abordagens de ensino-aprendizagem. As Diretrizes Gerais do Reuni rezam que a expansão educacional proposta deve ser pautada por “[...] reestruturações acadêmicas e curriculares que proporcionem maior mobilidade estudantil, trajetória de formação flexível, redução das taxas de evasão, utilização adequada dos recursos humanos e materiais colocados à disposição das universidades federais” (Brasil, 2007b, p. 9).

Essas são orientações que desafiam o sistema educacional brasileiro a superar concepções fragmentadas do conhecimento, currículos pouco flexíveis, viés disciplinar, precocidade na escolha da carreira profissional por parte dos estudantes e, principalmente, a lógica seletiva socialmente excludente.

Em suma, estreitos campos do saber contemplados nos projetos pedagógicos, precocidade na escolha dos cursos, altos índices de evasão de alunos, descompasso entre a rigidez da formação profissional e as amplas e diversificadas competências demandadas pelo mundo trabalho e, sobretudo, os novos desafios da sociedade do conheci- 
mento são problemas que, para sua superação, requerem modelos de formação profissional mais abrangentes, flexíveis e integradores (Brasil, 2007b, p. 8).

Neste artigo serão, entretanto, discutidos apenas alguns dos problemas enfrentados pelas universidades para cumprir o preconizado pelo Reuni. É importante lembrar que, dentre as diretrizes que cada universidade se pautou para apresentar sua proposta de adesão ao Reuni, destacam-se:

[...] a existência de flexibilidade curricular nos cursos de graduação que permita a construção de itinerários formativos diversificados e que facilite a mobilidade estudantil; a oferta de formação e apoio pedagógico aos docentes da educação superior que permitam a utilização de práticas pedagógicas modernas e o uso intensivo e inventivo de tecnologias de apoio à aprendizagem; e a disponibilidade de mecanismos de inclusão social a fim de garantir igualdade de oportunidades de acesso e permanência na universidade pública a todos os cidadãos (Brasil, 2007b, p. 10).

O alvo a ser atingido tem a ver com novas demandas da sociedade e o atual cenário mundial mais culturalmente diversificado, mais denso tecnologicamente, mais exigente de interdisciplinaridade. O currículo tradicional e disciplinarmente rígido passou a dar espaço a formas flexíveis de organização curricular em atenção às novas necessidades sociais de formação profissional. Assim, cada universidade que aderiu ao Reuni foi chamada a considerar:

[...] os desenvolvimentos efetivos das ações de modernização das estruturas curriculares, aliadas ao desempenho docente e discente, a evolução das avaliações CAPES, a evolução da produção científica do quadro docente e a participação do quadro docente da pós-graduação em atividades da graduação. Por fim, as medidas de inclusão social serão avaliadas a partir da evolução do perfil social e econômico dos estudantes ingressantes nas instituições e das políticas implementadas no campo da assistência estudantil e das ações afirmativas relacionadas ao sucesso ou fracasso nos índices de evasão (Brasil, 2007b, p. 20).

Os aspectos acima relacionados tratam de dimensões qualitativas da expansão propostas às universidades pelo Reuni. Do ponto de vista quantitativo, mais especificamente em relação ao número de vagas nos cursos presenciais de graduação, o que se pode constatar é que houve superação de metas já no primeiro ano desse Programa. O MEC estimou um aumento de $11 \%$ de vagas em 2008, passando de 132.451 para 146.762. Nas universidades federais, a oferta de vagas nesse ano foi de 147.277, mais 14.826 vagas além das previstas. (Brasil, 2009, p. 6)1. 
Gráfico 2 - Evolução das Vagas Ofertadas nas Universidades Federais

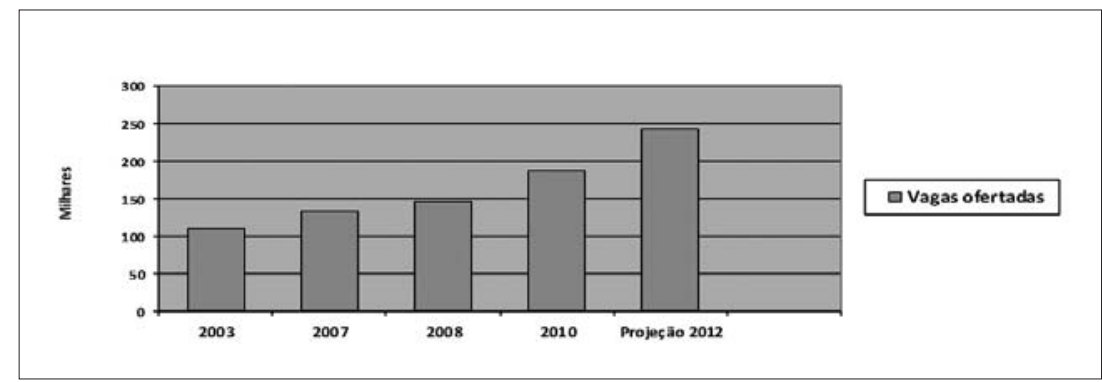

Fonte: Brasil. MEC. Inep (2013).

O primeiro ano do Programa Reuni também registrou o crescimento das matrículas projetadas ${ }^{2}$ nos cursos de graduação. Diz o relatório do MEC: “[...] a previsão inicial era de um aumento de $10 \% \mathrm{em}$ relação a 2007 (que totalizava 645.638 matrículas projetadas). Essa meta foi superada, chegando ao final de 2008 com 715.185 matrículas projetadas” (Brasil, 2009, p. 6). Esses números sinalizaram para uma provável nova situação das universidades em relação ao problema da evasão, no entanto isso não quer dizer que ele tenha sido resolvido. Nem tão pouco a questão da qualidade da educação pública, que também integra as diretrizes gerais do Reuni:

Ao lado da ampliação do acesso, com o melhor aproveitamento da estrutura física e do aumento do qualificado contingente de recursos humanos existente nas universidades federais, está também a preocupação de garantir a qualidade da graduação da educação pública. Ela é fundamental para que os diferentes percursos acadêmicos oferecidos possam levar à formação de pessoas aptas a enfrentar os desafios do mundo contemporâneo, em que a aceleração do processo de conhecimento exige profissionais com formação ampla e sólida. A educação superior, por outro lado, não deve se preocupar apenas em formar recursos humanos para o mundo do trabalho, mas também formar cidadãos com espírito crítico que possam contribuir para solução de problemas cada vez mais complexos da vida pública (Brasil, 2007b, p. 5).

Essas demandas de expansão de cursos e vagas às universidades e de melhoria da qualidade da graduação da educação pública exigiram a contratação de novos professores e funcionários técnico-administrativos. Os números chegaram, em 2011, a 69 mil docentes e a 105 mil funcionários técnico-administrativos considerando-se o conjunto das 59 universidades federais, o que exigiu uma previsão orçamentária de $\mathrm{R} \$ 23,6$ bilhões $^{3}$. Nenhuma das universidades federais ficou de fora do Reuni já no ano do início de sua implementação (2008), sinalizando para a concretização das pretendidas inovações e da expansão educacional. Assim, altos investimentos financeiros foram feitos pelo Gover- 
no Federal num segmento educacional estratégico ao desenvolvimento do país, que nem sempre teve os recursos de que precisava.

Investimentos que vieram ao encontro das demandas da população brasileira por desenvolvimento educacional e profissional em nível superior e que significaram novos desafios às universidades à inovação educacional e curricular, à produção de mais conhecimentos sobre formas criativas de pensar e fazer a educação superior.

\title{
Ampliação de Vagas Versus Qualidade do Ensino
}

O Reuni não se limitou, portanto, a propor o aumento quantitativo de vagas nas universidades públicas. Sugeriu, também, que se adotassem medidas para a elevação da qualidade da educação superior. Dois desafios de ordens distintas e difíceis de compatibilização num mesmo movimento. Como formar com mais qualidade, maior capacidade de crítica e de acompanhar as atuais inovações em diversas áreas do conhecimento diversificando-se o alunado ingressante?

Marra e Melo (2005) ressaltam que as Instituições de Ensino Superior (IES) têm sido cada vez mais cobradas com relação à eficiência, à qualidade, ao desenvolvimento de pesquisa e à produção de conhecimentos científicos que respondam aos desafios e aos problemas sociais, econômicos, políticos e culturais de forma concreta e contextualizada. De um lado, recebem pressões da sociedade civil por retornos em inovações que levem a melhorias na qualidade de vida em geral, pois as instituições públicas são financiadas pelo dinheiro público. De outro, há as pressões dos organismos supranacionais, no contexto da nova ordem econômica mundial, que reclamam maior eficiência na diminuição da pobreza e do analfabetismo aos governos centrais.

A universidade se vê, então, cobrada por maior envolvimento com as questões sociais, principalmente por meio da produção, divulgação e aplicação dos conhecimentos e pela democratização do acesso aos seus cursos. Severino (2008), porém, reclama a falta de projetos educacionais mais coerentes e consistentes com essas perspectivas ao afirmar que a universidade brasileira precisa ser campo mediador entre cidadania e democracia. Ele lembra que as políticas educacionais governamentais ainda carecem de maior consequência:

\begin{abstract}
Sempre embalado num discurso retórico em defesa da qualidade do ensino e da excelência da educação, e dos decorrentes corolários, a democratização da sociedade, a realização da cidadania, a melhoria de vida para seus destinatários diretos e indiretos, incluindo aí a inclusão no mercado de trabalho, o governo toma iniciativas alegadamente fundadas em argumentos técnicos e vai implementando ações nem sempre articuladas em torno de um projeto político-educacional orgânico (Severino, 2008, p. 82).
\end{abstract}


Severino argumenta que o governo deseja é “[...] atender mesmo ao mercado de trabalho, bem na linha do que estipula a teoria do capital humano [...]" e, com isso, correm o risco de tornarem-se “[...] dependentes das imposições políticas e das metas do poder executivo do país, mercantilizando sua produção acadêmica" (Severino, 2008, p.84). O autor se reporta a Oliveira que diz que as universidades públicas “[...] lutam, portanto, entre ajustar-se às políticas de educação superior e às demandas do mercado e desenvolver um projeto político-pedagógico próprio, coerente com a construção de sua autonomia” (Oliveira, 2006, p. 18).

Esse argumento constitui uma das linhas de crítica ao processo de expansão da educação superior no país proposto pelo Reuni, por conta da lógica de racionalização administrativa assumida por esse Programa, que poderia colocar em risco as possibilidades de uma mudança qualitativa, do ponto de vista social, do ensino.

Porto e Regnier (2003, p. 82) explicam que:

\begin{abstract}
As principais críticas ao crescimento acelerado do sistema brasileiro de ensino superior dirigem-se à sua possível perda de qualidade. Assume-se a premissa de que quantidade não combina com qualidade, ou ainda que se 'abrir' demais a entrada, não se tem como garantir o resultado final. Esta crítica é dirigida principalmente ao crescimento do número de novas instituições (e de estudantes por elas atendidos) que, em tese, teriam menor qualidade do que as demais já estabelecidas no contexto além de receberem como alunos os egressos do ensino médio com menor qualificação. O debate que estes entendimentos suscitam está longe de apresentar um consenso. A própria definição de qualidade é sujeita a múltiplas interpretações que envolvem graus elevados de subjetividade: a qualidade precisa sempre ser qualificada - qualidade de quê?
\end{abstract}

Neves, Raizer e Fachinetto (2007) consideram que estariam ocorrendo apenas “[...] mudanças de nomenclatura e não mudança importante no tipo de oferta de educação superior que poderia colaborar significativamente para a elevação do acesso e da interação com a sociedade". Segundo os autores, o número de jovens que concluem o ensino fundamental e a taxa de matrícula no ensino médio são muito baixos, mesmo com o aumento que tem se verificado nas vagas nesses níveis educacionais. Argumentam que há pouco investimento em educação básica, considerando-se a dívida social e educacional para com a população e a sua demanda por mais oportunidades.

Entre os fatores que têm contribuído (para a ampliação da procura por educação superior) destacam-se a valorização do conhecimento científico, a defesa dos direitos sociais (mais educação), a aspiração das famílias por mobilidade social através da educação, a necessidade de aquisição de 
mais competências para enfrentar o mercado de trabalho, etc. (Neves; Raizer; Fachinetto, 2007, p. 143).

Os censos socioeconômicos da graduação da UFMG, anos de 2003, 2004 e 2005, confirmam tais advertências. Os ingressantes seriam provenientes de extratos sociais médios, do ensino médio diurno e não profissional, de escolas particulares (apenas $40 \%$ originam da rede pública), solteiros, de cor branca, com cerca de 20 anos de idade e de famílias em que, pelo menos, um dos pais tem curso superior. Além disso, a maioria não trabalhava ao se candidatar ao concurso. Em contrapartida, $70 \%$ das vagas noturnas eram ocupadas por egressos de escolas públicas (UFMG, 2005). Ou seja, os estudantes oriundos de escolas públicas têm conseguido ingressar em universidades públicas. Porém, a maioria no período noturno em razão da necessidade de conciliar estudo e trabalho. Poucos ingressam em cursos como Medicina, Engenharia e Economia.

O entendimento das relações entre acesso e equidade na educação superior no Brasil não pode satisfazer-se com a interpretação dos números que caracterizam o processo recente de expansão desse nível de ensino entre nós. A expansão foi bastante expressiva, mas não suficiente para alterar o fato de que, na raiz do problema, persiste a realidade de uma pirâmide educacional profundamente perversa, que só permite que uma fração muito pequena de estudantes se aproxime efetivamente da educação superior (Neves; Raizer; Fachinetto, 2007, p. 129).

Estudo realizado por Mont'alvão Neto (2014, p. 437) sobre tendências das desigualdades de acesso ao ensino superior no Brasil, no período de 1982 a 2010 confirmam que “[...] as chances de estudantes chegarem ao ensino superior são influenciadas pelas origens socioeconômicas, pela estrutura familiar, pelo grupo racial, gênero, inserção no mercado de trabalho e localização regional". Segundo o autor, no período analisado, o efeito da classe social e da estrutura familiar na desigualdade de acesso a esse nível de ensino teria se mantido estável. No entanto, ele encontrou evidências para o aumento das vantagens das mulheres e para "[...] a diminuição das desvantagens de estudantes que precisam ou escolhem trabalhar, assim como de grupos de cor (Sic!) e de estudantes cujos pais têm alcance educacional limitado" (Mont'alvão Neto, 2014, p. 437). Esse estudo, contudo, não fez análises sobre a destinação desses acessos por áreas de conhecimento e cursos, mas mostra tendências que precisam ser mais profundamente conhecidas nas suas dimensões demográficas, sociais e culturais. Da mesma forma, é preciso considerar o efeito estrutura organizacional universitária sobre as tendências das desigualdades de acesso à universidade brasileira. Isso diz respeito ao que Boaventura de Sousa Santos (2001, p. 187) denomina impreparação estrutural da universidade para a mudança. Diz ele que: 
[...] duplamente desafiada pela sociedade e pelo Estado, a universidade não parece preparada para defrontar os desafios, tanto mais que estes apontam para transformações profundas e não para simples reformas parcelares. Aliás, tal impreparação, mais do que conjuntural, parece ser estrutural, na medida em que a perenidade da instituição universitária, sobretudo no mundo ocidental, está associada à rigidez funcional e organizacional, à relativa impermeabilidade às pressões externas, enfim, à aversão à mudança.

Teoricamente, as universidades seriam campo favorável à promoção de inovações, à produção crítica e à distribuição social do conhecimento. A diversidade, presente dentro e fora da sala de aula, precisa ser considerada como contribuição para fortalecer o projeto institucional e suas relações com as diferentes demandas sociais, econômicas e culturais.

Para Porto e Regnier (2003, p. 7), “[...] o acesso ao ensino, em seus diversos graus (e cada vez mais elevados), não é apenas um imperativo econômico correspondente à sociedade do conhecimento ou da informação. Ele é também um referencial político de expressão de índices de democracia e de justiça". Fazer um curso superior se tornou um anseio de muitos, mas, mais do que isso, é um direito que passa a fazer parte das aspirações de muitos jovens que veem nesse nível de ensino a possibilidade de realização pessoal, social e profissional.

Na visão da Unesco (1999, p. 246),

A experiência comum de numerosos países é que o ensino superior não é mais uma pequena parcela especializada ou esotérica da vida de um país. Ele se encontra no próprio coração das atividades da sociedade, é um elemento essencial do bem-estar econômico de um país ou região, um parceiro estratégico do setor do comércio e da indústria, dos poderes públicos, assim como das organizações internacionais.

A globalização econômica, financeira e cultural trouxe, nesse sentido, novos desafios, pois ao estimular a competição entre os países incide sobre as demandas por escolarização em níveis mais altos. Por isso,

[...] o acesso crescente e contínuo da população aos graus mais elevados de ensino torna-se uma medida tanto do potencial econômico (pela possibilidade de diferenciação competitiva) quanto de valoração / mensuração da meritocracia e da democracia praticada por uma nação. A educação agrega valor aos sistemas produtivos ao mesmo tempo em que se torna um valor superlativo de humanidade e do grau de civilidade e de desenvolvimento de um país (Porto; Regnier, 2003, p. 9). 
O potencial econômico dos países também passa a ser medido pelo nível de escolarização da população, correlação que estimula maiores investimentos no sistema educacional, eleva as chances dos jovens de concluir o ensino superior, tenciona os parâmetros da democracia e abre espaços para mais gente participar do desenvolvimento. Mas, segundo Silva Jr. e Sguissardi (2001),

[...] a reconfiguração da educação superior brasileira é parte de intenso processo de reformas, no interior de um radical movimento de transformações político-econômicas em nível mundial, com profundas repercussões no Brasil. Suas consequências para a identidade institucional da universidade brasileira serão inevitáveis, se concretizadas tais mudanças conforme diretrizes emanadas originalmente desses organismos multilaterais, em geral tão bem traduzidos domesticamente pelos responsáveis oficiais pela reforma do Estado e da Educação Superior em nosso país. (Silva Jr; Sguissardi, 2001, p. 271-272).

Como parte desse contexto, a reforma que aconteceu nas universidades federais brasileiras em decorrência da vigência do Reuni provocou mudanças significativas na estrutura de cada uma dessas instituições, dentre as quais, a principal talvez seja o aumento do número de estudantes provenientes de escolas públicas. Todavia, como alerta Oliveira (2006, p. 15),

Nesse processo de ajustamento, de sobrevivência e de desenvolvimento institucional, há indícios de que muitas universidades federais estejam assumindo perfil mais funcional e pragmático, o que pode distanciá-las paulatinamente do ideal de universidade como instituição social que se pauta, sobretudo, pela natureza das suas atividades, pela cultura e história institucional e pelo papel que desempenha no processo de emancipação da sociedade.

Não se pode, portanto, perder de vista as funções precípuas da universidade de promover a formação profissional de alta qualidade, a pesquisa e a produção de conhecimentos comprometida com o desenvolvimento social e econômico do país e em sintonia com sua base histórica e cultural.

Para Severino (2008, p. 87),

Na verdade, os desafios das universidades públicas são os mesmos de toda a educação pública, em todos os seus níveis e modalidades, resumindo-se no conflito dilemático que atravessa a realidade social brasileira da atualidade: o confronto entre uma educação pautada nas premissas da teoria do capital humano e uma educação que se quer identificada com a teoria da emancipação humana, entre uma educação que se coloca a serviço do mercado e uma outra que se quer a serviço da construção de uma condi- 
ção de existência mais humanizada, onde o trabalho é uma mediação essencial do existir histórico das pessoas e não um mero mecanismo da produção para o mercado. Sem prejuízo de seu compromisso de preparar as novas gerações para a esfera do trabalho, pelo adequado domí nio dos saberes científico e tecnológico, a educação não pode deixar de investir também no amadurecimento de uma nova consciência social e no aprimoramento da formação cultural dessas gerações. Desse núcleo aglutinador de suas tarefas, nenhuma universidade pode abrir mão sob pena de se descaracterizar integralmente e de comprometer sua identidade fundamental.

Observa-se, assim, que o processo de expansão de vagas na educação superior pública brasileira suscitou debates envolvendo teses sobre desenvolvimento de competências para o mercado de trabalho versus a necessidade de emancipação social de amplas camadas da população, os riscos à qualidade do ensino com a expansão quantitativa da oferta, cursos distanciados das necessidades sociais, conservação de uma estrutura rígida e burocrática das instituições universitárias mesmo com a adoção de um perfil mais funcional e pragmático.

Apesar das diferenças nas interpretações e análises, há um ponto comum a elas: as universidades são intimadas a primar pela excelência da educação que fornecem, a incentivar a qualificação dos seus servidores e a criar novas propostas pedagógicas que levem à constituição de um novo perfil discente. Isso significa não se esquecer de que o modelo tradicional de gestão acadêmica também precisa ser repensado, uma vez que o contexto institucional requer modificação, exigindo dos profissionais maior compromisso social no desempenho das suas funções.

O fato é que a oferta de vagas na educação superior pública no Brasil cresceu como foi proposto pelo Reuni. Entretanto, não se pode ignorar a existência de vários problemas gerados pela expansão ou por ela acentuados, dentre eles a evasão estudantil.

\section{O Reuni na UFMG}

A proposta que a UFMG apresentou ao MEC, em 2008, para o Reuni previa a implantação de 30 novos cursos e a ampliação da oferta de vagas em outros 24, no período entre 2008 e 2011. Além da ampliação do número de vagas em cursos de graduação já existentes e da oferta de novos cursos, determinava o crescimento das iniciativas de mobilidade estudantil, maior flexibilização dos currículos, integração entre graduação e pós-graduação, aumento da taxa de conclusão média dos cursos de graduação presenciais para $90 \%$ e da relação de alunos de graduação em cursos presenciais por professor para dezoito, conforme orientação do próprio Reuni.

Em decorrência dos avanços científicos e tecnológicos das últimas décadas, os cursos existentes nas IFES requerem aperfeiçoamen- 
tos em suas estruturas curriculares e metodológicas. Pensando nisso, a UFMG propôs a expansão integrada da graduação e da pós-graduação, o incentivo de práticas docentes de estudantes de pós-graduação, maior utilização da educação a distância, o desenvolvimento de novos currículos, abordagens multidisciplinares, o recurso a novas metodologias pedagógicas, a busca por formações inéditas, arrojadas e socialmente relevantes.

A UFMG também se comprometeu a aumentar as vagas no período noturno, propiciando mais oportunidades de ingresso aos alunos carentes e/ou trabalhadores, a desenvolver formas de apoio à permanência desses alunos e reduzir a evasão escolar (UFMG, 2008). A seguir serão analisadas mudanças ocorridas nessa universidade no cumprimento das metas acordadas com o Reuni.

A UFMG adotou, a partir do Vestibular 2012, o Exame Nacional do Ensino Médio (ENEM) como primeira etapa do processo seletivo, assim como o fizeram outras universidades federais. Para o Vestibular 2013, adotou o regime de cotas proposto pelo Decreto n. 7.824, de 11 de outubro de 2012, que dispõe sobre o ingresso nas universidades federais e nas instituições federais de educação profissional e tecnológica. Em seu $\operatorname{artigo} 2^{\circ}$, esse Decreto determina que

\begin{abstract}
As instituições federais vinculadas ao Ministério da Educação que ofertam vagas de educação superior reservarão, em cada concurso seletivo para ingresso nos cursos de graduação, por curso e turno, no mínimo cinquenta por cento de suas vagas para estudantes que tenham cursado integralmente o ensino médio em escolas públicas, inclusive em cursos de educação profissional técnica, [...] (Brasil, 2012b).
\end{abstract}

Em 2013, de acordo com o Relatório de Gestão 2010 a 2014 (UFMG, 2015), essa Universidade reservou $12,5 \%$ das vagas do concurso Vestibular 2013 para essa medida, cerca de 862 vagas das 6.670 ofertadas nos seus 75 cursos de graduação. Para tanto, seguiu três critérios (étnicos, socioeconômicos e origem de escola pública) e o aumento gradativo dessa proporção será considerado até chegar, em quatro anos, ao estabelecido pelo Decreto. (UFMG, 2015).

É importante salientar que, desde 2009, a UFMG adota uma política inclusiva nos seus processos seletivos, por intermédio do Programa de Bônus. No Vestibular 2012, 10,26\% dos ingressantes precisaram efetivamente do bônus para ingressar na instituição.

Essa Universidade, em 2011, de acordo com o Relatório de Gestão 2011 da UFMG (UFMG, 2012), contava com 50 cursos apoiados pelo Reuni, dos quais 27 eram inteiramente novos, sendo 16 noturnos e 11 diurnos. Os outros 23 eram cursos já existentes que criaram uma oferta noturna e/ou tiverem suas vagas ampliadas. A meta da universidade era criar até 2011 um total de 2136 novas vagas na graduação, sendo $67 \%$ 
desse total no período noturno. Ao todo foram criadas 2066, ou seja, $96,7 \%$ das prometidas ao Reuni. O restante estava aguardando a finalização de obras (UFMG, 2012).

Os quadros 1 e 2 trazem informações para o período de 2008 a 2012 sobre os cursos novos implantados e os que sofreram ampliação de vagas nessa Universidade.

Quadro 1 - Cursos Implantados na UFMG, 2008 - 2012

\begin{tabular}{|l|c|c|}
\hline \multicolumn{1}{|c|}{ Cursos } & Vagas & Turno \\
\hline Administração - noturno (Cidade de Montes Claros) & 40 & $\mathrm{~N}$ \\
\hline Antropologia & 40 & $\mathrm{~N}$ \\
\hline Aquacultura & 50 & $\mathrm{D}$ \\
\hline Arquivologia & 40 & $\mathrm{~N}$ \\
\hline Biomedicina & 40 & $\mathrm{~N}$ \\
\hline Ciência de Alimentos (Cidade de Montes Claros) & 40 & $\mathrm{~N}$ \\
\hline Ciência do Estado & 50 & $\mathrm{D}$ \\
\hline Ciências Socioambientais & 50 & $\mathrm{~N}$ \\
\hline Cinema de Animação e Artes Digitais & 40 & $\mathrm{~N}$ \\
\hline Conservação e Restauração de Bens Culturais Móveis & 30 & $\mathrm{D}$ \\
\hline Controladoria e Finanças & 50 & $\mathrm{D}$ \\
\hline Dança & 20 & $\mathrm{~N}$ \\
\hline Design & 60 & $\mathrm{~N}$ \\
\hline Design de Moda & 45 & $\mathrm{~N}$ \\
\hline Engenharia Aeroespacial & 50 & $\mathrm{D}$ \\
\hline Engenharia Agrícola e Ambiental (Cidade de Montes Claros) & 40 & $\mathrm{D}$ \\
\hline Engenharia Ambiental & 50 & $\mathrm{D}$ \\
\hline Engenharia de Sistemas & 50 & $\mathrm{~N}$ \\
\hline Engenharia Florestal (Cidade de Montes Claros) & 40 & $\mathrm{D}$ \\
\hline Formação Intercultural de Educadores Indígenas & 35 & $\mathrm{D}$ \\
\hline Gestão de Serviços de Saúde & 100 & $\mathrm{~N}$ \\
\hline Gestão Pública & 80 & $\mathrm{~N}$ \\
\hline Licenciatura em Educação do Campo & 35 & $\mathrm{D}$ \\
\hline Museologia & 40 & $\mathrm{D}$ \\
\hline Química Tecnológica & 40 & $\mathrm{~N}$ \\
\hline Relações Econômicas Internacionais & 50 & $\mathrm{~N}$ \\
\hline Curso Superior em Tecnologia de Radiologia & 80 & $\mathrm{~N}$ \\
\hline
\end{tabular}

Fonte: UFMG (2012). 
Quadro 2 - Cursos da UFMG que tiveram as Vagas Ampliadas, $2008-2012$

\begin{tabular}{|l|c|c|c|c|c|}
\hline Cursos & $\begin{array}{c}\text { Vagas } \\
\mathbf{2 0 0 8}\end{array}$ & $\begin{array}{c}\text { Vagas } \\
\mathbf{2 0 0 9}\end{array}$ & $\begin{array}{c}\text { Vagas } \\
\mathbf{2 0 1 0}\end{array}$ & $\begin{array}{c}\text { Vagas } \\
\mathbf{2 0 1 1}\end{array}$ & $\begin{array}{c}\text { Vagas } \\
\mathbf{2 0 1 2}\end{array}$ \\
\hline Arquitetura e Urbanismo & 90 & 150 & 150 & 150 & 150 \\
\hline Artes Visuais & 66 & 80 & 80 & 80 & 80 \\
\hline Ciências Biológicas & 160 & 200 & 200 & 200 & 200 \\
\hline Comunicação Social & 100 & 100 & 120 & 120 & 120 \\
\hline Educação Física & 120 & 120 & 120 & 120 & 150 \\
\hline Engenharia de Minas & 50 & 60 & 60 & 60 & 60 \\
\hline Engenharia de Controle e & 80 & 160 & 130 & 130 & 130 \\
\hline Automação & 80 & 90 & 90 & 90 & 90 \\
\hline Engenharia de Produção & 50 & 60 & 60 & 60 & 60 \\
\hline Estatística & 35 & 45 & 45 & 45 & 45 \\
\hline Farmácia & 132 & 132 & 212 & 212 & 212 \\
\hline Filosofia & 45 & 45 & 85 & 85 & 85 \\
\hline Física & 90 & 90 & 90 & 90 & 120 \\
\hline Fisioterapia & 60 & 75 & 75 & 75 & 75 \\
\hline Geografia & 80 & 80 & 120 & 120 & 120 \\
\hline Letras & 300 & 420 & 420 & 420 & 420 \\
\hline Matemática & 90 & 120 & 120 & 120 & 120 \\
\hline Música & 46 & 106 & 106 & 106 & 106 \\
\hline Nutrição & 60 & 72 & 72 & 72 & 72 \\
\hline Odontologia & 60 & 144 & 144 & 144 & 144 \\
\hline Química & 90 & 90 & 90 & 90 \\
\hline Sistema de Informação & 40 & 80 & 80 & 80 \\
\hline Terapia Ocupacional & 66 & 66 & 66 & 66 \\
\hline
\end{tabular}

Fonte: UFMG (2012).

Essa expansão de cursos e vagas para o desenvolvimento do Reuni de 2008 a 2012 na UFMG levou à previsão de um investimento de $\mathrm{R} \$$ 72.830.312,90, montante destinado aos programas de moradia, saúde, alimentação, mobilidade e extensão, às novas políticas de inserção, à construção, expansão e readequação de prédios e à melhoria da infraestrutura (UFMG, 2012).

A UFMG também buscou desenvolver metodologias fundamentadas nas tecnologias de informação e comunicação visando tornar o ensino-aprendizagem mais integrado, dinâmico e atraente. Criou o GIZ (Rede de Desenvolvimento de Práticas de Ensino Superior), uma linha de atuação institucional vinculada à Pró-Reitoria de Graduação, que tem como finalidades o aprimoramento das metodologias de ensino superior por meio de novas tecnologias e a reflexão contínua da prática docente, como formas de melhorar a qualidade do ensino ${ }^{4}$.

A UFMG investiu também no aumento das chances dos seus alunos de participarem de processos de mobilidade estudantil, permitindo que realizassem parte de seus cursos em outras instituições universitá- 
rias, do país ou do exterior. Tem também se mostrado aberta a receber alunos de instituições parceiras interessadas no mesmo fim. No entanto, como se observa nos quadros abaixo, a quantidade de programas de intercâmbios na UFMG e a quantidade de alunos que tiveram a oportunidade de fazer parte dos estudos no exterior, no período de 2008 a 2011, não foi muito expressiva.

Quadro 3 - Número de Programas de Intercâmbio na UFMG

\begin{tabular}{|c|c|c|c|}
\hline $\mathbf{2 0 0 8}$ & $\mathbf{2 0 0 9}$ & $\mathbf{2 0 1 0}$ & $\mathbf{2 0 1 1}$ \\
\hline 54 & 69 & 62 & 77 \\
\hline \multicolumn{4}{|c|}{ Fonte: UFMG (2012). } \\
Quadro 4 Número de Alunos da UFMG em Programas de \\
Intercâmbio no Exterior \\
\hline $\mathbf{2 0 0 8}$ & $\mathbf{2 0 0 9}$ & $\mathbf{2 0 1 0}$ & $\mathbf{2 0 1 1}$ \\
\hline 268 & 395 & 309 & 416 \\
\hline
\end{tabular}

Fonte: UFMG (2012).

A criação do Programa Ciências Sem Fronteiras pelo Governo Federal no final de 2011 serviu de estímulo para uma busca crescente pelos graduandos de intercâmbio em universidades da Alemanha, EUA, França, Itália e Reino Unido. A UFMG buscou corresponder a esse propósito.

O mesmo pode ser dito com relação às mudanças que dizem respeito à flexibilização curricular. Muitos cursos modificaram sua matriz curricular com o intuito de se adequarem ao que é proposto pela Câmara de Graduação da UFMG no documento sobre flexibilização. Isso fez surgir demandas de reforço das condições institucionais preexistentes:

Os novos cursos, as modificações nos cursos já existentes, as novas formas de interação entre a graduação e a pós-graduação, além de exigirem alterações no funcionamento dos colegiados, implicarão em mudanças na administração central, mais especificamente nas Pró-reitorias de ensino [...] muitos dos novos cursos passarão a funcionar no turno noturno, providências adicionais deverão ser tomadas, desde o cuidado com condições materiais sustentáveis até a disponibilização dos recursos de natureza mais acadêmica, indispensáveis à qualificação da formação, tais como, entre outros itens, bibliotecas e laboratórios (UFMG, 2008, p. 61).

A UFMG estimou, na proposta apresentada ao Reuni, a contratação de 406 docentes com dedicação exclusiva, 350 funcionários técnico-administrativos de nível médio e 150 de nível superior. Os dados apresentados abaixo indicavam situações de defasagem: 
Quadro 5 - Cargos Docentes Ocupados e Vagos em 2011

\begin{tabular}{|c|c|c|}
\hline Cargo ocupado & Cargo provimento & Cargo vago \\
\hline 2712 & 244 & 210 \\
\hline \multicolumn{3}{|c|}{ Fonte: UFMG (2012). } \\
\hline
\end{tabular}

Quadro 6-Cargos Técnico-Administrativos Ocupados e Vagos em 2010

\begin{tabular}{|c|c|}
\hline Cargo ocupado & Cargo vago \\
\hline 4052 & 221 \\
\hline
\end{tabular}

Fonte: UFMG (2012).

A superlotação de salas de aula advinda com o Reuni despertou a necessidade de atenção. Para tanto, a UFMG passou a contar com prédios novos dotados de salas de aula e auditórios equipados com multimídia: o CAD1 (Centro de Atividades Didáticas das Ciências Naturais), concluído em 2011, o CAD2 (Centro de Atividades Didáticas das Ciências Humanas), em 2012, e o CAD3 (Centro de Atividades Didáticas das Ciências Exatas), ainda em construção.

É importante ressaltar, entretanto, que a expansão do ensino da graduação na UFMG em atendimento às diretrizes do Reuni se realizou em curto período de tempo e foi marcada por diversos problemas. $\mathrm{O}$ Relatório de Gestão 2011 da instituição (UFMG, 2012) relacionou quatro como os principais.

O primeiro deles se refere à falta de preenchimento das vacâncias de cargo técnico administrativo, pois por quase dez anos, a UFMG não obteve autorização para a realização de concurso público para esse provimento. O segundo decorre da necessidade de maior acompanhamento e apoio aos alunos beneficiados pelas ações afirmativas no que diz respeito à vida acadêmica e sua inserção no mercado de trabalho, considerando que os diversos programas de assistência estudantil já implementados precisam ser reforçados.

O terceiro problema mencionado pelo referido Relatório tem a ver com o aumento do número de chamadas de candidatos aprovados em processo seletivo para assegurar a ocupação do maior número possível das vagas oferecidas e aumento do número de vagas remanescentes. Os quadros abaixo trazem informações a esse respeito. Tais fenômenos associados à utilização do ENEM, a partir de 2011, como primeira etapa do exame de seleção. Seguramente, há efeitos da mudança do processo seletivo sobre o perfil dos graduandos, mas não se dispõe de dados sobre isso.

Por último, o quarto problema listado pelo Relatório de Gestão 2011, vem a persistência do problema da evasão estudantil. É importante dizer que a instituição ainda carece de estudos para conhecer melhor as causas desse fenômeno e as medidas para minimizá-lo. 
Reuni e Expansão Universitária na UFMG de 2008 a 2012

Quadro 7 - Vagas Remanescentes nos Novos Cursos Criados pela UFMG no Contexto do Reuni

\begin{tabular}{|c|c|c|c|c|c|}
\hline \multirow{2}{*}{ Curso } & \multirow{2}{*}{ Turno } & \multirow{2}{*}{$\begin{array}{l}\text { Vagas } \\
\text { ofertadas }\end{array}$} & \multicolumn{3}{|c|}{$\begin{array}{c}\text { Vagas } \\
\text { remanescentes }\end{array}$} \\
\hline & & & 2010 & 2011 & 2012 \\
\hline Administração (Montes Claros) & $\mathrm{N}$ & 50 & 02 & 14 & 13 \\
\hline Antropologia & $\mathrm{N}$ & 40 & 03 & 11 & 22 \\
\hline Aquacultura & $\mathrm{D}$ & 50 & 12 & 25 & 76 \\
\hline Arquivologia & $\mathrm{N}$ & 40 & 02 & 05 & 20 \\
\hline Biomedicina & $\mathrm{N}$ & 40 & - & 05 & 10 \\
\hline $\begin{array}{l}\text { Ciência de Alimentos (Montes } \\
\text { Claros) }\end{array}$ & $\mathrm{N}$ & 40 & 02 & 07 & - \\
\hline Ciência do Estado & $\mathrm{D}$ & 50 & 05 & 13 & 34 \\
\hline Ciências Socioambientais & $\mathrm{N}$ & 50 & - & 05 & 14 \\
\hline $\begin{array}{l}\text { Cinema de Animação e Artes } \\
\text { Digitais }\end{array}$ & $\mathrm{N}$ & 40 & 03 & 16 & 12 \\
\hline $\begin{array}{l}\text { Conservação e Restauração de } \\
\text { Bens Culturais Móveis }\end{array}$ & $\mathrm{D}$ & 30 & - & 04 & 03 \\
\hline Controladoria e Finanças & $\mathrm{D}$ & 50 & 03 & 10 & 31 \\
\hline $\begin{array}{l}\text { Curso Superior em Tecnologia de } \\
\text { Radiologia }\end{array}$ & $\mathrm{N}$ & 80 & - & 06 & 30 \\
\hline Dança & $\mathrm{N}$ & 20 & - & 01 & 03 \\
\hline Design & $\mathrm{N}$ & 60 & 05 & 17 & 22 \\
\hline Design de Moda & $\mathrm{N}$ & 45 & 05 & 11 & 25 \\
\hline Engenharia Aeroespacial & $\mathrm{D}$ & 50 & 04 & 09 & 05 \\
\hline $\begin{array}{l}\text { Engenharia Agrícola e Ambiental } \\
\text { (Montes Claros) }\end{array}$ & $\mathrm{D}$ & 40 & 02 & 13 & 15 \\
\hline Engenharia Ambiental & $\mathrm{D}$ & 50 & 04 & 05 & 09 \\
\hline Engenharia de Sistemas & $\mathrm{N}$ & 50 & - & 04 & 10 \\
\hline $\begin{array}{l}\text { Engenharia Florestal (Montes } \\
\text { Claros) }\end{array}$ & $\mathrm{D}$ & 40 & 04 & 10 & 10 \\
\hline $\begin{array}{l}\text { Formação Intercultural de } \\
\text { Educadores Indígenas }\end{array}$ & $\mathrm{D}$ & 35 & 04 & 09 & 10 \\
\hline Gestão de Serviços de Saúde & $\mathrm{N}$ & 100 & 22 & 20 & 65 \\
\hline Gestão Pública & $\mathrm{N}$ & 80 & 07 & 19 & 29 \\
\hline $\begin{array}{l}\text { Licenciatura em Educação do } \\
\text { Campo }\end{array}$ & $\mathrm{D}$ & 35 & 04 & 25 & 39 \\
\hline Museologia & $\mathrm{D}$ & 40 & 02 & 02 & 11 \\
\hline Química Tecnológica & $\mathrm{N}$ & 40 & 01 & 11 & 15 \\
\hline $\begin{array}{l}\text { Relações Econômicas } \\
\text { Internacionais }\end{array}$ & $\mathrm{N}$ & 50 & 04 & 11 & 22 \\
\hline
\end{tabular}

Fonte: UFMG (2012). 
Quadro 8 - Vagas remanescentes em cursos da UFMG que tiveram vagas expandidas com o Reuni

\begin{tabular}{|c|c|c|c|c|}
\hline \multirow{2}{*}{ Curso } & \multirow{2}{*}{$\begin{array}{c}\text { Vagas } \\
\text { ofertadas }\end{array}$} & & & \\
\hline & & 2010 & 2011 & 2012 \\
\hline Arquitetura e Urbanismo & 150 & 05 & 12 & 04 \\
\hline Artes Visuais & 80 & 01 & 06 & 26 \\
\hline Ciências Biológicas & 200 & - & - & 36 \\
\hline Comunicação Social & 120 & 02 & 15 & 05 \\
\hline Educação Física & 150 & 14 & 13 & 08 \\
\hline Engenharia de Minas & 60 & 06 & - & - \\
\hline Engenharia de Controle e Automação & 130 & 11 & 25 & 25 \\
\hline Engenharia de Produção & 90 & 05 & 03 & 11 \\
\hline Engenharia Metalúrgica & 60 & 05 & 10 & - \\
\hline Estatística & 45 & 15 & 15 & 41 \\
\hline Farmácia & 212 & 12 & 06 & 45 \\
\hline Filosofia & 85 & 12 & 29 & 24 \\
\hline Física & 120 & 32 & 38 & 37 \\
\hline Fisioterapia & 75 & 03 & 15 & 16 \\
\hline Geografia & 120 & 39 & 24 & 39 \\
\hline Letras & 420 & 83 & 16 & 96 \\
\hline Matemática & 120 & 76 & 126 & 200 \\
\hline Música & 106 & 26 & 72 & 80 \\
\hline Nutrição & 72 & 05 & 18 & - \\
\hline Odontologia & 144 & 05 & 14 & 15 \\
\hline Química & 90 & 33 & 30 & 31 \\
\hline Sistema de Informação & 80 & 04 & 06 & 10 \\
\hline Terapia Ocupacional & 66 & 09 & 32 & 27 \\
\hline
\end{tabular}

Fonte: UFMG (2012).

Os dados acima mostram aumento considerável, em 2011 e 2012, na oferta de vagas remanescentes tanto nos cursos novos como nos que tiveram suas vagas ampliadas. As incidências maiores verificaram-se nos cursos de Aquacultura, Ciência do Estado, Licenciatura em Educação no Campo, Estatística, Matemática e Música. Mas os demais cursos da UFMG também apresentaram o problema, fazendo elevar a taxa geral de vagas remanescentes na instituição, que apresenta tendência crescente conforme se vê no quadro abaixo:

Quadro 9 - Vagas Remanescentes na UFMG, 2010 - 2012

\begin{tabular}{|c|c|c|c|}
\hline Vagas & $\mathbf{2 0 1 0}$ & $\mathbf{2 0 1 1}$ & $\mathbf{2 0 1 2}$ \\
\hline Ofertadas & 6600 & 6610 & 6670 \\
\hline \multirow{2}{*}{ Remanescentes } & 790 & 1104 & 1708 \\
& $11,9 \%$ & $16,7 \%$ & $25,6 \%$ \\
\hline
\end{tabular}

Fonte: UFMG (2012). 
É importante esclarecer que as vagas remanescentes do primeiro semestre letivo são destinadas aos alunos da UFMG na forma de rematrícula e reopção de curso. Já as vagas remanescentes do segundo semestre letivo são ofertadas ao público externo para transferência e obtenção de novo título. No entanto, devido à baixa procura por alguns cursos e à alta taxa de evasão, nem todas as vagas disponíveis estão sendo preenchidas, situação que afetou o cumprimento de uma das metas do Programa Reuni que era elevar a taxa de conclusão média dos cursos de graduação para $90 \%$.

Modificações na relação entre retenção e evasão de alunos dependem de medidas de gestão acadêmica e não somente dos artifícios para o preenchimento das vagas ociosas, pois, de alguma forma e em certa medida, estratégias de apoio pedagógico aos que correm o risco de não permanecerem na universidade podem concorrer para evitar os eventos de abandono, desistência e jubilamento de alunos. Soma-se a isso a necessidade de considerar se a implementação do Plano Nacional de Assistência Estudantil (PNAES) pela UFMG tem trazido contribuição para o tratamento da evasão estudantil por essa Universidade.

Segundo Aranha, Pena e Ribeiro (2012, p. 330), em estudo sobre os quatro primeiros anos de vigência de programas de inclusão na UFMG, dentre os quais o Reuni,

Um dado importante que deve ser considerado na elaboração de políticas de permanência na universidade é que a evasão não ocorre de forma homogênea entre as Grandes Áreas do conhecimento. No conjunto de discentes analisados, até o final do $1^{\circ}$ semestre de 2011, o maior percentual da evasão ocorreu entre aqueles que ingressaram em cursos da área de Ciências Exatas e da Terra (11,53\%). Os menores percentuais de evasão, por outro lado, foram observados nas áreas de Engenharias, Saúde e Biológicas, correspondendo, respectivamente, a $4,20 \%, 4,55 \%$ e $4,76 \%$.

Na avaliação dos resultados alcançados pelo Reuni, é preciso considerar que as instituições de ensino superior, no caso as federais, enfrentam dificuldades cotidianas que não podem ser associadas exclusivamente ao Reuni. Por outro lado, essa avaliação não pode ser feita sem levar em conta a história, particularidades da região, especificidades, estágios de desenvolvimento, tamanho e cultura organizacional de cada instituição que aderiu a esse Programa.

Em todas elas, certamente houve intensificação do trabalho de docentes e técnico-administrativos, particularmente com relação à oferta de ensino de graduação, em razão das demandas dos novos projetos pedagógicos, das atividades de controle acadêmico e dos processos seletivos de ingresso. 


\section{Considerações Finais}

O Reuni surge num momento e contexto de aumento dos investimentos do Governo Federal na educação pública brasileira. Este artigo trouxe elementos para a discussão se seus propósitos de democratização da educação superior foram alcançados. É preciso, contudo, considerar que esse processo que não é simples e nem tão pouco imediato à aplicação de recursos financeiros às universidades.

Em razão das implicações regulatórias e gerenciais inerentes à lógica de racionalização técnica, da qual a definição de metas sobre percentual de aprovação discente e de relação do número de alunos por professor como condição para liberação dos recursos são expressões, esse Programa provocou debates polêmicos e resistências de comunidades universitárias à sua implantação.

Os diversos desafios colocados por ele, especialmente os acadêmicos, são complexos. O problema da tendência crescente de surgimento de vagas remanescentes é um bom indicador nesse sentido. Trata-se de um Programa com objetivos estratégicos que requerem, contudo, avanços na concepção da gestão universitária, gestão que tem características especiais, que guardam potenciais de tensões e conflitos de diferentes ordens.

Debates sobre o projeto de universidade - que se tem ou não se tem, que se quer ter ou não se quer ter - emergem e fazem aflorar temas como autonomia, participação democrática, condições de trabalho, infraestrutura adequada, indissociabilidade do ensino, pesquisa e extensão, interpenetração entre as esferas pública e privada, formação aligeirada dos estudantes, qualidade social dos produtos e processos universitários, dentre outros.

O Reuni se inseriu no contexto de profundas transformações pelas quais vive a universidade brasileira e alimentou os debates sobre as noções de eficiência e produtividade acadêmica ao propor o chamado Acordo de metas. A despeito do viés gerencialista, é importante ressaltar a importância da cobrança que fez às universidades de maior atenção às dimensões qualitativas decorrentes do processo de expansão dos cursos e vagas, que incluem esforços de aperfeiçoamento e atualização curricular, assistência estudantil e apoio pedagógico docente, especialmente aos professores com ingresso recente na carreira.

Este artigo trouxe resultados da pesquisa realizada sobre o cumprimento das metas de expansão de vagas e de criação de novos cursos pela UFMG no contexto desse Programa, inclusive sobre efeitos não esperados ou agravados que comprometeram a eficácia da política em curso.

Constatou-se que a UFMG cumpriu quase integralmente as metas prometidas em relação à expansão quantitativa de vagas e novos cursos. Implantou 27 novos cursos de graduação, 90,0\% dos 30 previstos. 
Não houve expansão de vagas em apenas um curso de graduação dos 24 previstos. Das 2136 novas vagas na graduação prometidas para 2011, criou 2066 (96,7\%), de acordo com o Relatório de Gestão 2011. Criou cursos noturnos, adotou o sistema de bônus e, a partir do Vestibular 2013, o sistema de cotas, ampliando as chances de ingresso de mais estudantes trabalhadores, afrodescendentes e egressos de escolas públicas.

A UFMG investiu em instalações para atividades didáticas (CAD), dois novos prédios foram construídos e um terceiro está em construção, estabeleceu convênios com instituições nacionais e estrangeiras destinados à política de mobilidade estudantil e abriu novos concursos para contratação de pessoal docente e técnico-administrativo.

No entanto, verificou-se que ainda há vulnerabilidades que comprometem a eficácia da sua política de expansão de vagas e cursos. O número de vagas que remanescem é alto e apresenta nos anos investigados forte tendência ascendente. Dois fatores concorrem para essa situação contraditória com os objetivos da expansão universitária: o não preenchimento de todas as vagas oferecidas pelos cursos e a evasão discente, um problema que não é novo, mas que apresenta facetas originais, que demandam investigação aprofundada. Outra vulnerabilidade se refere à defasagem no quadro de pessoal, situação que compromete os trabalhos acadêmicos e administrativos da instituição, especialmente nos seus aspectos qualitativos, nas possibilidades de concretização dos objetivos relacionados às inovações pedagógicas e didáticas apregoadas pelo Reuni.

Portanto, a concretização do Reuni pela UFMG vem se dando de forma positiva, mas requer acompanhamento sistemático e intervenções dirigidas aos pontos embaraçosos que fragilizam seu desempenho institucional, alguns deles identificados neste artigo.

Recebido em 09 de abril de 2015 Aprovado em 15 de outubro de 2015

\section{Notas}

1 Disponível em: <http://portal.mec.gov.br/sesu/arquivos/pdf/>. Acesso em: 04 abr. 2011.

2 Projeta-se o total de alunos matriculados na universidade tomando como base o número de vagas de ingresso.

3 Fonte: <www.secom.gov.br>. Acesso em: 04 abr. 2011.

4 Disponível em: <http://giz.lcc.ufmg.br>. Acesso em: 04 abr. 2011.

\section{Referências}

BRASIL. Decreto n. 6.096, de 24 de abril de 2007. Institui o Programa de Apoio a Planos de Reestruturação e Expansão das Universidades Federais - Reuni. Diário Oficial da União [da] República Federativa do Brasil, Brasília, DF, 25 abr. 2007a. Seção I. P. 4. 
BRASIL. Ministério da Educação. Reuni: Reestruturação e Expansão das Universidades Federais (Diretrizes Gerais). Brasília, DF, 2007b. Disponível: <www. secom.gov.br>. Acesso em: 04 abr. 2011.

BRASIL. Ministério da Educação. Programa de Apoio a Planos de Reestruturação e Expansão das Universidades Federais: Reuni 2008. Brasília, DF, 2009. Disponível em: <http://portal.mec.gov.br/sesu/arquivos/pdf/diretrizesreuni. pdf >. Acesso em: 04 abr. 2011.

BRASIL. MEC/Inep. Censo da Educação Superior 2011: divulgação dos principais resultados do censo da educação superior 2011. Brasília, DF, 2012a. Disponível em: <http://sistemascensosuperior.inep.gov.br/censosuperior_2011/>. Acesso em: 04 abr. 2011.

BRASIL. Decreto n. 7.824, de 11 de outubro de 2012. Dispõe sobre o ingresso nas universidades federais e nas instituições federais de ensino técnico de nível médio. Diário Oficial da União [da] República Federativa do Brasil, Brasília, DF, 15 out. 2012b. Seção I. P. 6.

BRASIL. MEC/Inep. Censo da Educação Superior 2013. Brasília, DF, 2014. Disponível em: <http://download.inep.gov.br/educacao_superior/censo_superior/ apresentacao/2014/coletiva_censo_superior_2013.pdf>. Acesso em: 30 set. 2015.

MARRA, Adriana Ventola; MELO, Marlene Catarina de Oliveira Lopes. A Prática Social de Gerentes Universitários em uma Instituição Pública. Revista de Administração Contemporânea, Curitiba, v. 9, n. 3, p. 9-31, jul./set. 2005.

MONT'ALVÃO NETO, Arnaldo Lopo. Tendências das Desigualdades de Acesso ao Ensino Superior no Brasil: 1982-2010. Educação \& Sociedade, Campinas, v. 35, n. 127, p. 417-441, abr./jun. 2014.

NEVES, Clarissa Eckert Baeta; RAIZER, Leandro; FACHINETTO, Rochele Fellin. Acesso, Expansão e Equidade na Educação Superior: novos desafios para a política educacional brasileira. Sociologias, Porto Alegre, v. 9, n. 17, p. 124-157, jan./ jun. 2007.

OLIVEIRA, João Ferreira de. Reforma da Educação Superior: mudanças na gestão e metamorfose das universidades públicas. In: PEREIRA, Filomena Maria de Arruda; MULLER, Maria Lúcia R. Educação na Interface Relação Estado/Sociedade. Cuiabá: EDUFMT/Capes, 2006. P. 11-21.

PINTO, José Marcelino de Rezende. O Acesso à Educação Superior no Brasil. Educação \& Sociedade, Campinas, v. 25, n. 88, p. 727-756, out. 2004.

PORTO, Cláudio; REGNIER, Karla. O Ensino Superior no Mundo e no Brasil: condicionantes, tendências e cenários para o horizonte 2003-2025. Brasília: Ministério da Educação, 2003. Disponível em: <http://mecsrv04.mec.gov.br/univxxi/pdf/cenes3.pdf>. Acesso em: 31 mar. 2011.

SANTOS, Boaventura de Sousa. Pela Mão de Alice: o social e o político na pós-modernidade. São Paulo: Cortez, 2001.

SEVERINO, Antônio Joaquim. O Ensino Superior Brasileiro: novas configurações e velhos desafios. Educar, Curitiba, n. 31, p. 73-89, 2008.

SILVA JR., João dos Reis; SGUISSARDI, Valdemar. As Novas Faces da Educação Superior no Brasil: reforma do Estado e mudanças na produção. São Paulo: Cortez, 2001.

UNESCO. O Ensino Superior no Século XXI: visão e ações. In: Tendências da Educação Superior para o Século XXI. Brasília: UNESCO/CRUB, 1999. 
UNIVERSIDADE FEDERAL DE MINAS GERAIS (UFMG). Censo Socioeconômico dos Alunos de Graduação da UFMG. Belo Horizonte, 2005. Disponível em: $<$ www.ufmg.br/censo>. Acesso em: 29 jul. 2011.

UNIVERSIDADE FEDERAL DE MINAS GERAIS (UFMG). Proposta da UFMG para o Reuni 2008. Belo Horizonte, 2008. Disponível em: <http://www.ufmg.br/ Reuni>. Acesso em: 03 set. 2010.

UNIVERSIDADE FEDERAL DE MINAS GERAIS (UFMG). Relatório de Gestão da UFMG 2011. Belo Horizonte, MG, 2012. Disponível em: <http:// www2.ufmg.br/ proplan >. Acesso em 16 nov. 2012.

UNIVERSIDADE FEDERAL DE MINAS GERAIS (UFMG). Relatório de Gestão da UFMG 2010 a 2014. Belo Horizonte, MG, 2015. Disponível em: <http://www. ufmg.br/relatoriodegestao/2010-2014>. Acesso em: 28 set. 2015.

Edileusa Esteves Lima é graduada em Letras e especialista em Gestão de Instituições Federais de Ensino Superior pela UFMG, especialista em Revisão de Textos pela PUC Minas e mestre em Gestão Social, Educação e Desenvolvimento Local pelo Centro Universitário UNA.

E-mail: edileusacegrad@gmail.com

Lucília Regina de Souza Machado é graduada em Ciências Sociais e mestra em Educação pela Universidade Federal de Minas Gerais, doutora em Educação: História, Política, Sociedade pela Pontifícia Universidade Católica de São Paulo e pós-doutorado em Sociologia do Trabalho pelo Institut de Recherches sur les Sociétés Contemporaines (Iresco) do CNRS, França.

E-mail:1smachado@uai.com.br 